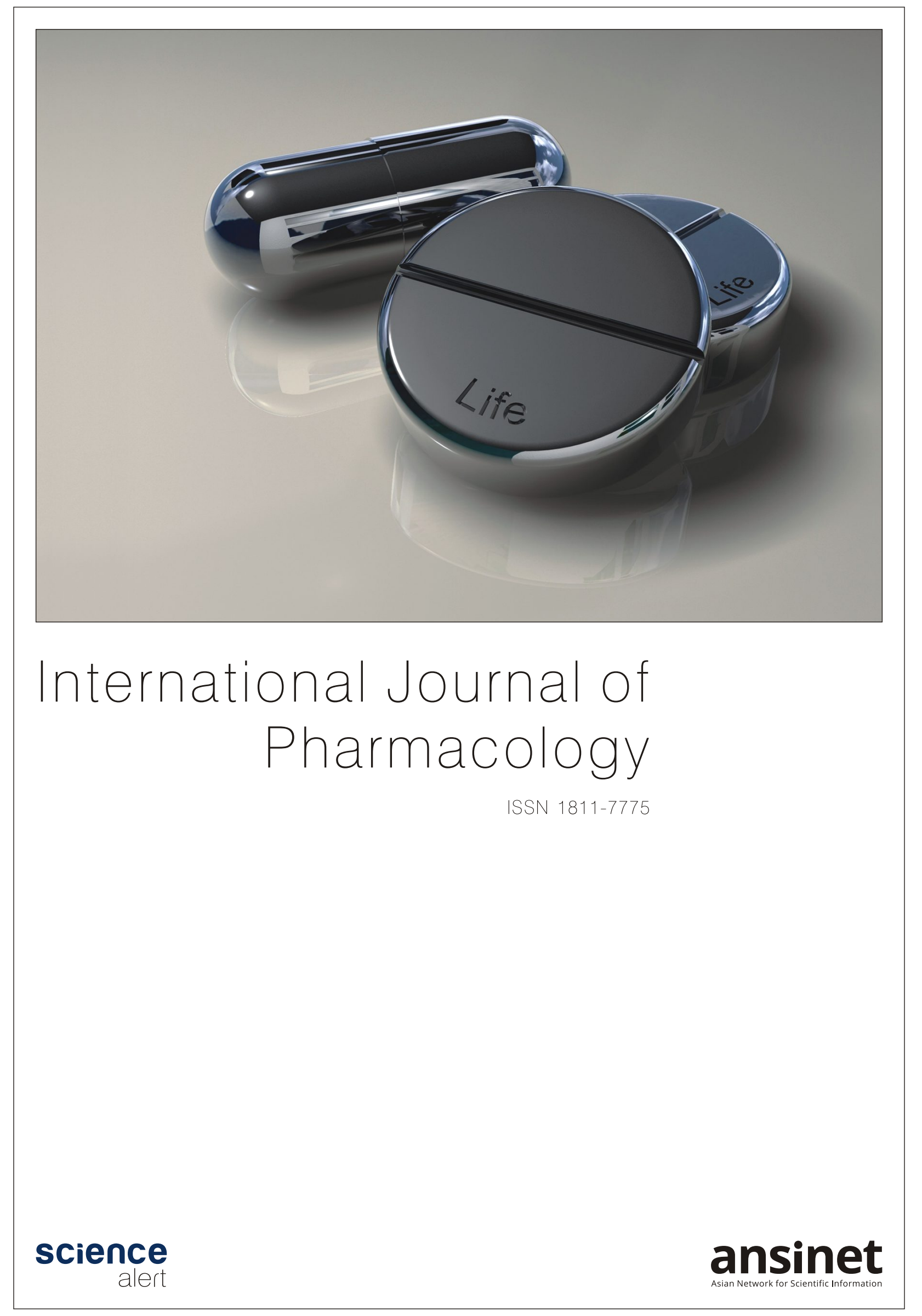




\title{
Research Article Defensive Mechanism in Human Cholangiocarcinoma Cells Against Hypoxia by Cyanidin-3-glucoside Treatment
}

\author{
${ }^{1}$ Guang-Hua Xie, ${ }^{2}$ Wei Xie, ${ }^{1}$ Heyun Piao and ${ }^{3}$ Dan Li \\ ${ }^{1}$ Department of Hepatobiliary Surgery, Yanbian University Hospital, Yanji, Jilin, 130000, China \\ ${ }^{2}$ Department of Ophthalmology, The Second Hospital of Jilin University, Changchun, Jilin, 130000, China \\ ${ }^{3}$ Department of Physiology, Anatomy and Genetics, University of Oxford, Parks Road, Oxford, OX1 3PT, UK
}

\section{Abstract}

Background and Objective: Cyanidin-3-glucoside (C3G) is one of the major bioactive compounds in anthocyanins, which have been shown to prevent a large spectrum of diseases. It has been reported that hypoxia is a common characteristic of many types of solid tumor and that the hypoxia-inducible factor $1 \alpha$ (HIF-1 $1 \alpha$ ) plays an important role in the process of angiogenesis and metastasis in cancer cells. The objective of this study was to explore the effects of C3G on HIF-1 $\alpha$ activation in cholangiocarcinoma (CCA) cells. Materials and Methods: The human cholangiocarcinoma cell line QBC939 was used in this study. Hypoxic conditions were achieved by using the chemical hypoxia agent cobalt chloride or incubation at $1 \% \mathrm{O}_{2}$. and $\mathrm{MTT}$ assay, Luciferase reporter assay, flow cytometric apoptosis assay, western blot, RT-PCR and immuno fluorescence methods were used to determine the C3G efficacy. Results: C3G markedly decreased the hypoxia-induced accumulation of HIF-1 $\alpha$ reporter activity and protein expression in a dose-dependent manner and exerted a large apoptotic effect in CCA cells. Furthermore, C3G reduced expression of several genes downstream of HIF- $1 \alpha$, such as vascular endothelial growth factor and erythropoietin, without affecting the expression level of HIF-1 $\alpha$ mRNA, thus indicating that C3G acts as an inhibitor of HIF-1 $\propto$ mRNA translation. Conclusion: This study provides a novel strategy to develop a low toxicity, high efficiency and multi-target natural active substance for the treatment of cancers.

Key words: HIF-1a, cyanidin-3-glucoside, hypoxia, cholangiocarcinoma, angiogenesis and metastasis in cancer cells

Received: September 24, $2018 \quad$ Accepted: December 13, $2018 \quad$ Published: March 15, 2019

Citation: Guang-Hua Xie, Wei Xie, Heyun Piao and Dan Li, 2019. Defensive mechanism in human cholangiocarcinoma cells against hypoxia by cyanidin-3-glucoside treatment. Int. J. Pharmacol., 15: 361-369.

Corresponding Authors: Guang-Hua Xie, Department of Hepatobiliary Surgery, Yanbian University Hospital, Yanji, Jilin, 130000, China Tel: 0086-15526770890

Dan Li, Department of Physiology, Anatomy and Genetics, University of Oxford, Parks Road, Oxford, OX1 3PT, UK Tel: 0044-1865272547

Copyright: @ 2019 Guang-Hua Xie et al. This is an open access article distributed under the terms of the creative commons attribution License, which permits unrestricted use, distribution and reproduction in any medium, provided the original author and source are credited.

Competing Interest: The authors have declared that no competing interest exists.

Data Availability: All relevant data are within the paper and its supporting information files. 


\section{INTRODUCTION}

Cholangiocarcinoma (CCA) is one of the most malignant tumors that arises from biliary tract epithelial cells. It is often hard to diagnose owing to its special anatomic location and growth patterns ${ }^{1}$. There are typically a lack of specific signs or symptoms in the early stage, until the bile duct has been completely blocked, so the large majority of CCA patients present at an advanced stage and already have distant metastases ${ }^{1,2}$. In addition, CCA is relatively resistant to treatment with chemotherapy and radiation therapy and the five-year survival rate is only $5 \%$ and this has not substantially improved over the past three decades ${ }^{3}$. Chemotherapy drugs that commonly used to treat CCA have a high cost, toxic side effects and are susceptible to drug resistance. Developing a low toxicity, safe and effective treatment agent is therefore one of the most urgent tasks for the effective therapy of CCA.

In recent years, increasing numbers of new drugs have been developed from natural plant active substances which have been used for therapeutic purposes in traditional and folk medicine ${ }^{4}$. Cyanidin-3-glucoside (C3G) (Fig. 1a) is a monomeric compound isolated from anthocyanins, which are biologically active components found in blackberries and other food products 5 . It can scavenge free radicals and catalyse biochemical reactions by regulating gene expression processes. It has been reported that C3G affects the cell cycle, inflammatory responses ${ }^{6}$, tumor growth ${ }^{7}$, metastasis ${ }^{8}$ and many other physiological and pathological processes. However, little is known about the potential of C3G in retarding the antioxidant response in cancer cells and the underlying molecular mechanisms are not well defined.

Hypoxia is a common character in many types of solid cancers. Tumor cells grow faster than non-invasive cells and form large solid tumor masses, leading to obstruction and compression of the blood vessels surrounding these masses, resulting in a hypoxic microenvironment ${ }^{9}$. Hypoxia modulates the expression of genes that mediate physiological and cellular adaptive responses, including angiogenesis, apoptosis, cell proliferation and resistance to chemotherapy ${ }^{10-12}$. The key transcriptional regulator of the hypoxic response is the hypoxia-inducible factor (HIF)-1, which plays an important regulatory role in oxygen homeostasis ${ }^{13}$. HIF-1 consists of two subunits: HIF- $1 \alpha$ and HIF-1 $\beta$. HIF- $1 \alpha$ levels and activity are regulated by cellular oxygen concentration. In normoxic state, HIF- $1 \alpha$ is rapidly degraded by the ubiquitin-proteasome pathway and is almost undetectable in cytoplasm. Whereas during hypoxia, HIF-1 $\alpha$ expression increases as a result of decreased ubiquitination and degradation and it subsequently translocates to the nucleus where it binds to HIF- $1 \beta /$ p 300 , to regulate the transcription and expression of various downstream target genes ${ }^{14}$.

Although a number of hypoxia-associated proteins involved in cancer growth and proliferation have been well studied in many types of cancers, the effect of natural compounds on the hypoxia-mediated pathways and its downstream target genes in CCA remain mostly unknown. In the present study, using chemical hypoxia agent cobalt chloride $\left(\mathrm{CoCl}_{2}\right)$ and $1 \% \mathrm{O}_{2}$ to mimic the effects of hypoxia on the human CCA cell line QBC939, investigated the protective effects of C3G on the proliferation and apoptosis of QBC939 cells and their underlying mechanisms. This study might provide a novel strategy to develop a low toxicity, high efficiency natural active substance for the treatment of CCA.

\section{MATERIALS AND METHODS}

Cell culture: The human cholangiocarcinoma cell line QBC939 (ATCC, Manassas, VA, USA) was cultured in DMEM supplemented with $10 \%$ fetal bovine serum at $37^{\circ} \mathrm{C}$ in a $5 \%$ $\mathrm{CO}_{2}$ humidified atmosphere for normoxic conditions. Hypoxic conditions were achieved by adding different concentrations of $\mathrm{CoCl}_{2}$ into the culture media, then incubated under otherwise standard culture conditions. In some experiments, the cells were incubated in a gas-controlled chamber (Thermo Electron Corp., Marietta, OH, USA) maintained at $1 \% \mathrm{O}_{2}, 94 \%$ $\mathrm{N}_{2}$ and $5 \% \mathrm{CO}_{2}$ at $37^{\circ} \mathrm{C}$.

Determination of cell viability (MTT assay): QBC939 cells were seeded onto 96-well plates at a density of $1 \times 10^{5}$ cells/well and incubated overnight. The cells were then pre-treated with different concentrations of C3G $(0,30,50,100$ and $200 \mu \mathrm{M}$ ). After $24 \mathrm{~h}$ exposure period, media was removed and cells were washed with phosphate-buffered saline (PBS), followed by incubation with $5 \mathrm{mg} \mathrm{mL}^{-1}$ MTT [3-(4,5dimethylthiazol-2-yl)-2,5-diphenyltetrazolium bromide] (Sigma, St. Louis, MO, USA) in culture medium for an additional $4 \mathrm{~h}$. Afterward, $200 \mu \mathrm{L}$ of lysis buffer (isopropyl alcohol containing $10 \%$ Triton X-100 and $0.1 \mathrm{~N} \mathrm{HCl}$ ) was added to dissolve the formazan formed and then measured spectrophotometrically at $570 \mathrm{~nm}$.

Luciferase reporter assay: The ability of the C3G to inhibit hypoxia inducible factor was determined by HRE-dependent reporter assay as previously described ${ }^{15}$. Briefly, at $50-80 \%$ confluence, QBC939 cells were transfected with a HIF- $1 \alpha$ 
reporter construct pGL3-HRE-Luc using Lipofectamine plus reagent (in vitro gen, Carlsbad, CA, USA). Following $24 \mathrm{~h}$ incubation, the cells were treated with various concentrations of C3G for 30 min and then incubated in $200 \mu \mathrm{M}$ of $\mathrm{CoCl}_{2}$ for $16 \mathrm{~h}$. A Luciferase assay was then performed using dual-luciferase reporter assay system according to the instructions of the manufacturer (Promega).

Apoptosis assay: Annexin V-staining was performed using Annexin V-FITC apoptosis detection kit (BD Biosciences, CA, USA) following the instructions of the manufacturer. Briefly, after incubation, QBC939 cells were harvested, washed with PBS ( $\mathrm{pH}$ 7.4) and centrifuged, then stained with Annexin V-FITC and $2 \mathrm{mg} \mathrm{mL}^{-1}$ propidium iodide in binding buffer (10 mM Hepes, pH 7.4, $140 \mathrm{mM} \mathrm{NaCl}, 2.5 \mathrm{mM} \mathrm{CaCl}_{2}$ ) for $15 \mathrm{~min}$ at $37^{\circ} \mathrm{C}$ in the dark. The samples were then analysed using a FACScan flow cytometer in combination with Cell Quest software (Becton Dickinson).

Western blot analysis: Whole-cell extracts were obtained by lysing QBC939 cells in ice-cold RIPA buffer (Sigma, USA) supplemented with the protease inhibitor cocktail (BD Biosciences, San Diego, CA, USA). Protein concentration was determined by the Bradford method. About $50 \mu \mathrm{g}$ of protein was separated by SDS-PAGE and the expression of HIF- $1 \alpha$ protein in QBC939 cells was compared. Antibodies and their sources were as follow: anti-HIF-1 $\alpha, 1: 1000$ (Cell Signaling Technology), anti- $\beta$-actin, 1:1000 (Santa Cruz) and anti-topo$\mathrm{I}, 1: 1000$ (Santa Cruz). Following the binding of an appropriate secondary antibody, proteins were visualized by enhanced chemiluminescence (Amersham Pharmacia Biotech, Buckinghamshire, UK).

RT-PCR analysis: Total RNA from QBC939 cells was obtained using RNA Mini kit (Qiagen, Valencia, CA, USA). Complementary DNA was synthesized from $1 \mu \mathrm{g}$ of total RNA in a $20 \mu \mathrm{L}$ reverse transcription reaction mixture according to the manufacturer's protocol (Roche, Switzerland). The PCR primers were: HIF-1 $\alpha$, 5'-CTCAAAGTCCGACAGCCTCA-3' (sense) and 5'-CCCTGCAGTAGGTTCTGCT-3' (antisense); VEGF, 5'-GCTCTACCTCCACCATGCCAA-3' (sense) and 5'-TGGAAGATGTCCACCAGGGTC-3' (antisense); EPO, 5'CACTTTCCGCAAACTCTTCCG-3' (sense) and 5'-GTCA CAGCTTGCCACCTAAG-3' (antisense); GAPDH, 5'-ACCACAGTC CATGCCATCAC-3' (sense) and 5' -TCCACCACCCTGTT GCTGTA$3^{\prime}$ (antisense). The oligonucleotide sequences of the reaction products were confirmed by sequencing.
Immuno fluorescence: Cultured QBC939 cells were fixed with $4 \%$ paraformaldehyde and permeabilized with $0.2 \%$ Triton $\mathrm{X} 100$ and $1 \%$ bovine serum albumin (BSA). Cells were then processed for immunoreactivity with rabbit anti-HIF- $1 \alpha(1: 500$, Cell Signaling Technology) in blocking solution (1\% BSA) overnight at $4{ }^{\circ} \mathrm{C}$. After washing with PBS several times, fixed cells were incubated with anti-rabbit antibody conjugated to Alexa Flour ${ }^{\oplus}-488$ (1:1000, Molecular Probes) in 1\% BSA respectively, for $1 \mathrm{~h}$ (room temperature). Upon washing with PBS, nuclear staining was then performed with 4',6diamidino-2-phenylindole (DAPI, 1:1000, Sigma).

Statistical analysis: Data were expressed as Mean \pm SEM. All statistical analyses were conducted by using SPSS version 13.0 statistical software package. Comparisons between groups for statistical significance was carried out with a 2-tailed paired Student $\mathrm{t}$-test and $\mathrm{p}$-value of less than 0.05 was considered statistically significant in all cases.

\section{RESULTS}

C3G inhibits hypoxia induced HIF-1 $\alpha$ dependent reporter gene expression: Cell viability and cytotoxicity was assessed by using MTT assay. After treating with C3G (30, 50, 100 and $200 \mu \mathrm{M}$ ) for $24 \mathrm{~h}$, no significant alteration of cell viability was observed relative to the untreated control group in QBC939 cells, indicated that cell proliferation was not affected by C3G (Fig. 1b). After cells were transiently transfected with the HIF-1 $\alpha$-regulated luciferase reporter vector, cells were further incubated with $200 \mu \mathrm{M} \mathrm{CoCl}$ in the presence of various concentration of C3G for $12 \mathrm{~h}$. A substantial increase of luciferase activity was observed in cells cultured in hypoxic conditions, whereas HIF-1 $\alpha$ reporter activity was substantially suppressed by C3G in a dose-dependent manner (Fig. 1C).

\section{C3G inhibits hypoxia induced HIF-1 $\alpha$ protein expressions:}

Under normal conditions, HIF-1 $\alpha$ protein was undetectable in QBC939 cells. However, when cells were exposed for $12 \mathrm{~h}$ to the different concentrations of $\mathrm{CoCl}_{2}, \mathrm{HIF}-1 \alpha$ protein levels increased dramatically and presented in a dose dependent effect (Fig. 2a). To assess the C3G efficiency, different concentrations of $\mathrm{C} 3 \mathrm{G}$ were added in cells $30 \mathrm{~min}$ before $\mathrm{CoCl}_{2}$ $(200 \mu \mathrm{M})$ treatment. After $12 \mathrm{~h}$ incubation, C3G exerted dose-dependent inhibition of HIF-1 $\alpha$ protein levels induced by $\mathrm{CoCl}_{2}$ in QBC939 (Fig. 2b), indicating that under hypoxic conditions, HIF- $1 \alpha$ accumulation was strongly suppressed by C3G in cholangiocarcinoma cells. 
<smiles>O=C(O[C@@H]1O[C@H](CO)[C@@H](O)[C@H](O)[C@H]1O)/C(=C/c1c(O)cc(O)cc1Cl)c1ccc(O)c(O)c1</smiles>
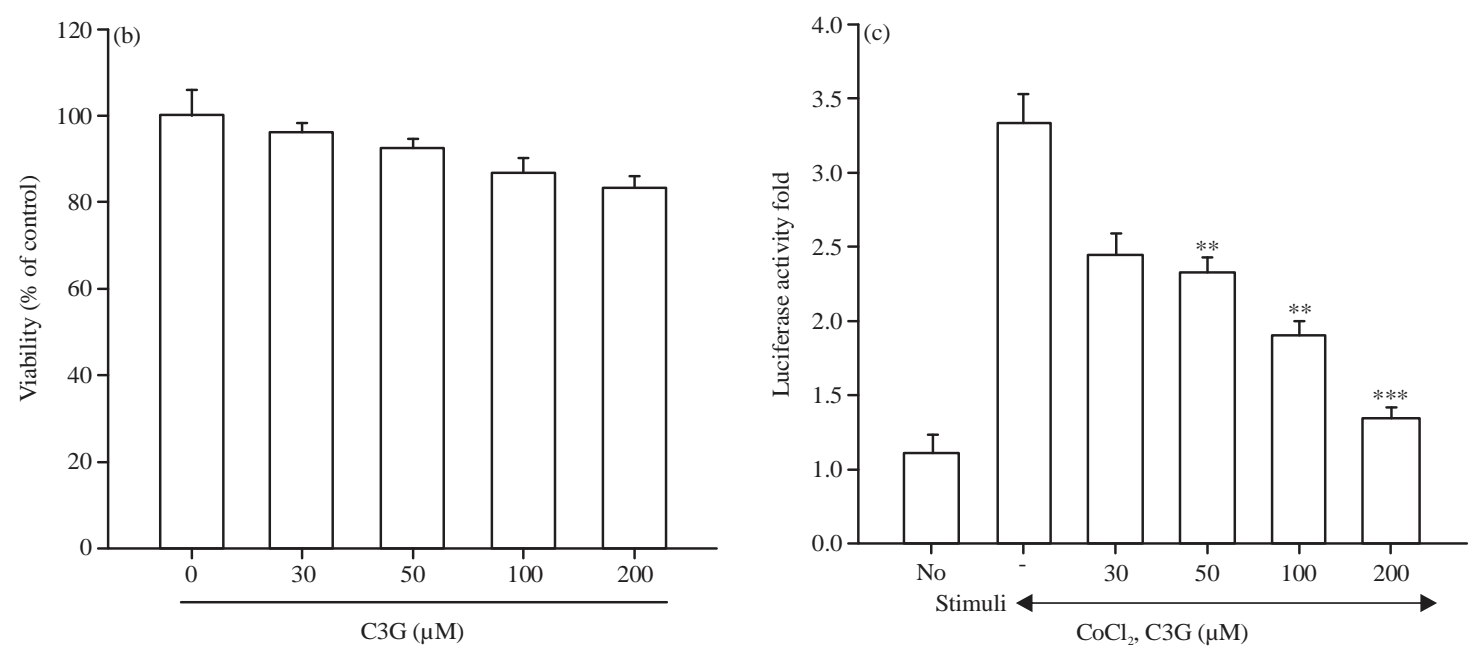

Fig. 1(a-c): (a) Chemical structure of cyanidin-3-glucoside (C3G), (b) Effect of C3G on QBC939 cells viability and (c) Effect of C3G on HRE-mediated reporter gene expression under hypoxia

${ }^{* *} \mathrm{p}<0.05,{ }^{* * *} \mathrm{p}<0.001$ compared with incubated in $\mathrm{CoCl}_{2}$ without $\mathrm{C} 3 \mathrm{G}$ treatment
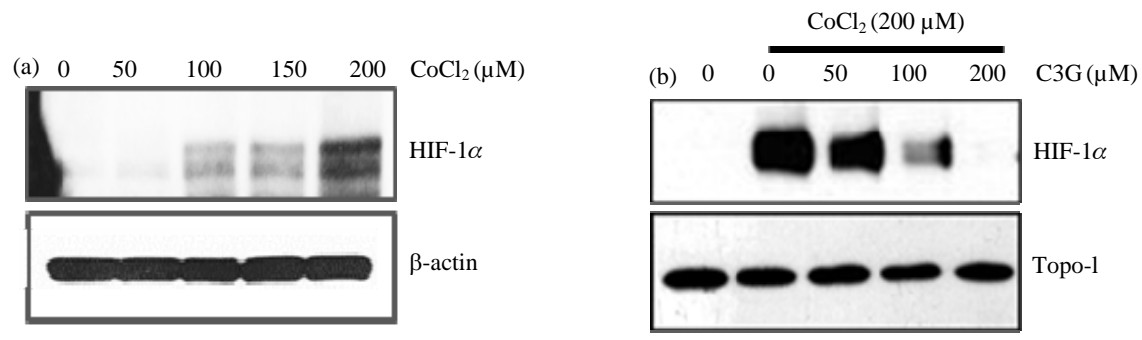

Fig. 2(a-b): (a) Expression of HIF-1 $\alpha$ protein in QBC939 cells exposed to the $\mathrm{CoCl}_{2}$ and (b) Absence or presence of the C3G

C3G promotes apoptosis in human cholangiocarcinoma

cells: The effect of C3G on QBC939 cell death was also confirmed by measuring apoptosis using flow cytometry after double staining cells with annexin $V$ and propidium iodide (PI). As shown in Fig. 3, following treatment with increasing C3G concentration from $50-200 \mu \mathrm{M}$ for $12 \mathrm{~h}$, it was cleared that the percentage of cells in the apoptotic stage (the bottom and top right quadrants represent early and late apoptosis) was enhanced compared with the untreated control. The C3G treatments with 50, 100 and $200 \mu \mathrm{M}$ were enhanced late apoptotic cell population to $15.5,17.9$ and $22.4 \%$ from $1.8 \%$ (non-treated group), respectively. Indeed, C3G treatments also induced elevation of early apoptotic cell population to 10.9, 12.8 and $15.2 \%$ from $5.4 \%$ (non-treated group), respectively. Whereas, necrotic cell population also increased in a dose dependent manner but slightly increased. This effect 


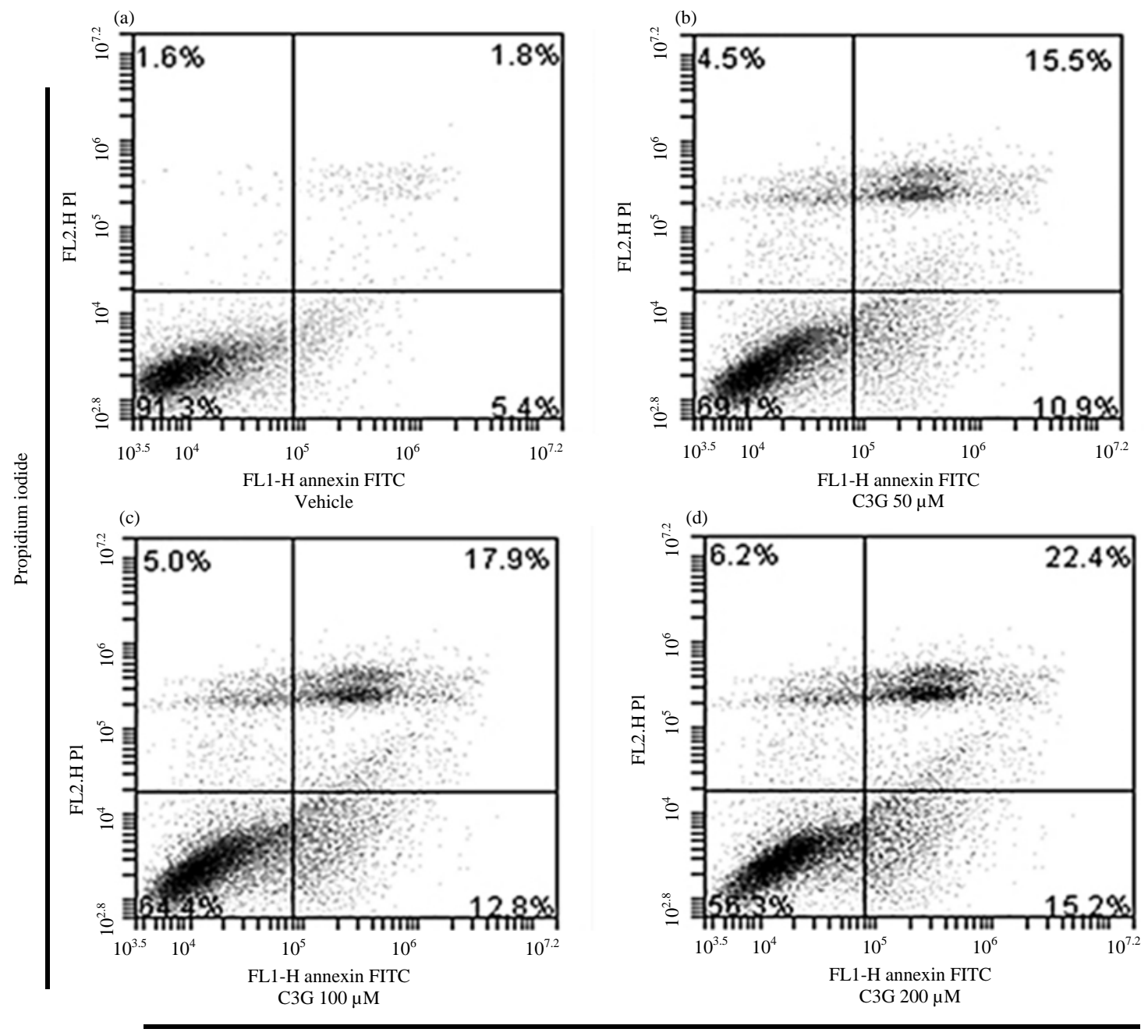

Annexin V-FITC

Fig. 3(a-d): Annexin V-FITC and PI staining to evaluate apoptosis in QBC939 cells following C3G treatment. QBC939 cells were treated with C3G (50, 100 and $200 \mu \mathrm{M}$ for $24 \mathrm{~h}$ ), incubated with annexin V-FITC and PI and analyzed using flow cytometry. In each panel the lower left quadrant shows cells, which are negative for both PI and annexin V-FITC, upper left quadrant shows only PI positive cells, which are necrotic. The lower right quadrant shows annexin positive cells (early apoptotic) and the upper right quadrant shows annexin and PI positive cells (late apoptosis cells)

presented in a dose-dependent manner, suggesting that C3G exerted a strong apoptotic effect on human cholangiocarcinoma cells. These results supported the hypothesis that C3G enhancement of cell death involved initiation of apoptosis.

C3G inhibits hypoxia induced nuclear HIF-1 $\alpha$ expression in human cholangiocarcinoma cells: An immunofluorescence assay was used to confirm whether HIF-1 $\alpha$ protein was accumulated in the nucleus to activate transcription of hypoxia-regulated genes post-hypoxic conditions. Figure 4 showed the intracellular localization of HIF-1 $\alpha$ in QBC939 cells by immunostaining with polyclonal anti-HIF-1 $\alpha$ antibody. Under normoxic $\left(21 \% \mathrm{O}_{2}\right)$ conditions, QBC939 cells expressed very weak HIF-1 $\alpha$ immunoreactivity in the nucleus, while after exposed to hypoxia $\left(1 \% \mathrm{O}_{2}\right)$, a strong nuclear signal of HIF- $1 \alpha$ was detected in QBC939 cells. Interestingly, nuclear expression of HIF- $1 \alpha$ was abolished following C3G treatment under hypoxic conditions $\left(1 \% \mathrm{O}_{2}\right)$, indicating that $\mathrm{C} 3 \mathrm{G}$ inhibited the transcription of hypoxia-regulated genes.

C3G decreases expression of HIF-1 $\alpha$ target genes in human cholangiocarcinoma cells: The expression of erythropoietin (EPO) and vascular endothelial growth 


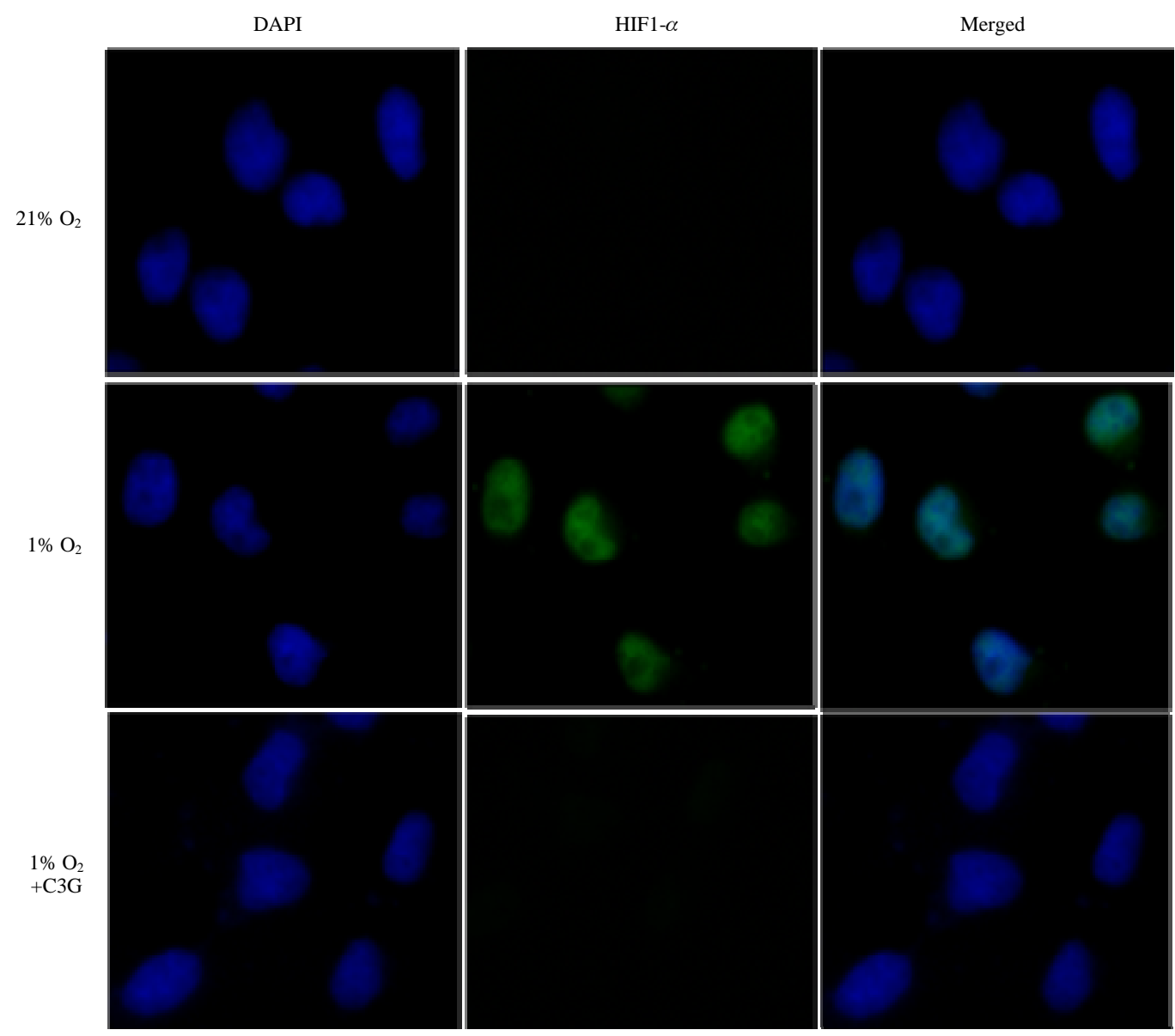

Fig. 4: Effect of C3G on the hypoxia induced HIF-1 $\alpha$ accumulation in QBC939 cells. Fluorescent micrographs showed DAPI (blue) and HIF-1a (green) immunostaining of QBC939 cells

factor (VEGF) were involved in tumor cell proliferation, angiogenesis, invasion and metastasis, with both being regulated by HIF- $1 \alpha$. After exposed to $200 \mu \mathrm{M} \mathrm{CoCl}_{2}$ for $12 \mathrm{~h}$, EPO and VEGF mRNA levels were measured using RT-PCR analysis in QBC939 cells. As expected, $\mathrm{CoCl}_{2}$ leads to enhanced EPO and VEGF mRNA levels. Treatment cells with C3G 30 min before $\mathrm{COCl}_{2}$ resulted in a dose-dependent inhibition of EPO and VEGF mRNA expression (Fig. 5). HIF-1 $\alpha$ mRNA levels were not affected by hypoxia.

\section{DISCUSSION}

Three potentially novel findings are presented in this study. First, C3G inhibits hypoxia induced HIF-1 $\alpha$ reporter activity and protein expression in human cholangiocarcinoma cells in a dose-dependent manner. Secondly, C3G exerts a strong apoptotic effect in human cholangiocarcinoma cells and does not induce any toxicity. Finally, C3G attenuates up-regulation of HIF-1 $\alpha$ target genes, such as EPO and VEGF.
C3G is a member of the polyphenol family, largely present in food and vegetables from a Mediterranean diet ${ }^{16,17}$. It is probably the best-known and most investigated anthocyanin, having potential beneficial effects in various human pathologies ${ }^{18,19}$. An increasing number of studies suggested that the dietary intake of phytochemicals is a good substitute for anticancer agents ${ }^{20,21}$, as phytochemicals possess antioxidant and radical scavenging effects, which may reduce the risk of cancer ${ }^{22}$. Shanmugam et al. ${ }^{23}$ summarized that numerous medicinal plant-derived compounds could modulate the activation of diverse oncogenic transcription factors in various tumor models such as hepatoma, breast cancer, leukemia and prostate cancer. However, how C3G effects the HIF-1 $\alpha$ transcription factors in human cholangiocarcinoma has not yet been explored.

HIF- $1 \alpha$ was shown to play a central role in mediating $\mathrm{O}_{2}$-dependent transcriptional responses ${ }^{24}$. Elevated expression of HIF-1 $\alpha$ protein has been observed in many human cancer cell types and is associated with a worse prognosis ${ }^{25}$. In the 
present study, over expression of HIF-1 $\alpha$ was also detected in QBC939 cells in the hypoxic state and expressed in a dose-dependent manner. Following treatment with C3G, there was a significant reduction of the hypoxia induced HIF- $1 \alpha$ reporter activity and protein expression as well as a pro-apoptotic effect in QBC939 cells. These results are therefore, in agreement with other findings, that C3G modulates intracellular redox status and prevents HIF-1 $\alpha$ stabilization in response to chronic hypoxia in human endothelial cells ${ }^{19}$.

Furthermore, the present research examined the induction of HIF-1 $\alpha$ under hypoxic conditions using immunofluorescence staining. HIF- $1 \alpha$ expression was observed in the nucleus as a result of hypoxic stimulation in QBC939 cells, whereas it was not expressed under normoxic conditions, indicating that nuclear translocation is necessary for regulating gene transcription. This supported the concept that under conditions of normal oxygen tension, the HIF- $1 \alpha$ protein subunits are constitutively expressed but rapidly degraded by HIF prolyl hydroxylases (PHD) and the proteasome von Hipple-Lindau (VHL) factor, thereby silencing HIF-1 $\alpha$ activity. However, in the low oxygen environment, HIF- $1 \alpha$ is stabilized and subsequently translocated into the nucleus ${ }^{26}$, wherein HIF-1 $\alpha$ initiates transcription of a wide range of genes (such as EPO and VEGF), which may help cells to adapt to a low oxygen supply ${ }^{27}$ (Fig. 6). VEGF is a signalling protein that promotes the growth of new blood vessels. It is a potent angiogenic factor that increases peripheral oxygen delivery by stimulating angiogenesi ${ }^{28}$. The EPO is the principal hormone that stimulates RBC growth and differentiation ${ }^{29}$.
VEGF and EPO have both been identified as angiogenic molecules, stimulating in vitro proliferation, migration and angiogenesis ${ }^{30}$. To the best of author's knowledge, this is the first report describing that EPO and VEGF mRNA levels are enhanced in CCA cells during hypoxia. These findings are in accordance with previously obtained evidence from HepG2 liver cancer and breast cancer MDA-MB-231 cells ${ }^{30,31}$. In

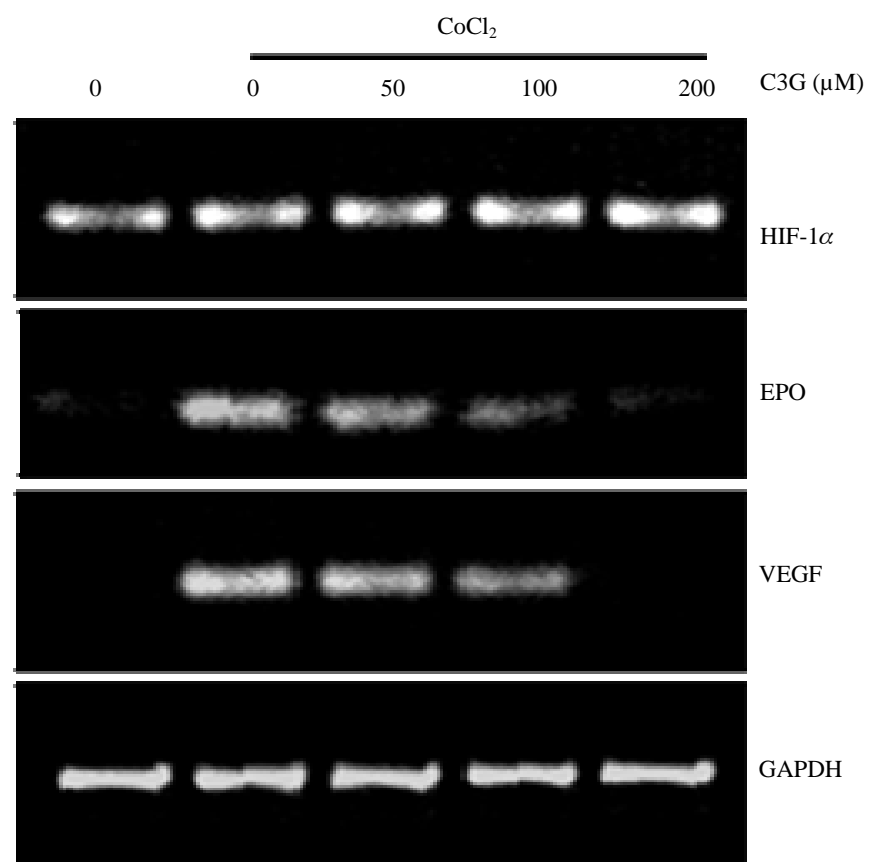

Fig. 5: Effect of C3G on hypoxia induced HIF-1 $\alpha$ regulated gene products in QBC939 cells

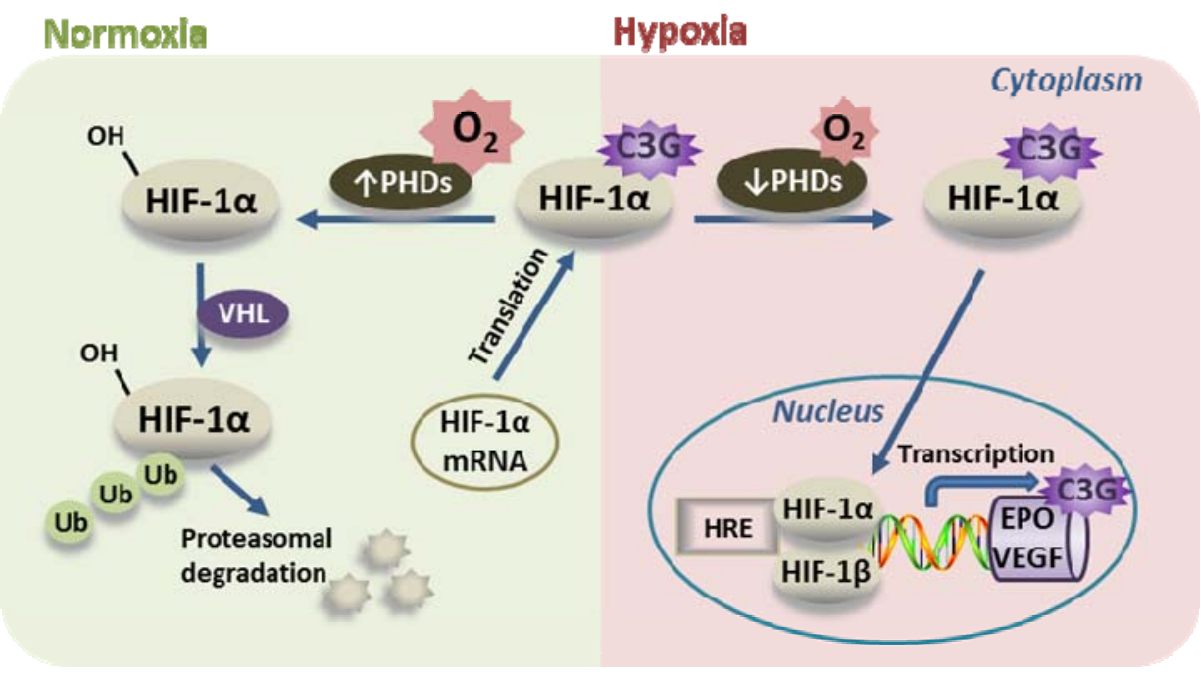

Fig. 6: Schematic detailing of C3G on the regulation of hypoxia-inducible factor $1 \alpha$ (HIF-1 $\alpha$ ) and its downstream transcription factors under normoxic and hypoxic conditions 
addition, C3G pre-treatment of QBC939 cells significantly reduces the hypoxia induced EPO and VEGF mRNA levels, but not HIF- $1 \alpha$, thus suggesting that C3G strongly inhibits HIF- $1 \alpha$ protein degradation without affecting the expression level of HIF- $1 \propto$ mRNA, indicating it acts as an inhibitor of HIF-1 $\alpha$ mRNA translation. Further research will be considered to test the C3G in vivo for the prevention and treatment of animal models of CCA.

\section{CONCLUSION}

This research reports for the first time that $\mathrm{C} 3 \mathrm{G}$ provides an enhancing effect on hypoxia induced apoptosis and that it suppresses HIF-1 $\alpha$ and its downstream transcription factors in CCA cells. These results strongly support the hypothesis that C3G, as well as other dietary plant polyphenols, might be a potential therapeutic strategy to sensitize cancer cells to hypoxia and provide a rationale for the development of a low toxicity, high efficiency natural active substance for the treatment of tumors.

\section{SIGNIFICANCE STATEMENT}

Cholangiocarcinoma (CCA) is leading cause of death due to late discovery and lack of effective treatment. Developing a low toxicity, safe and effective treatment agent is therefore one of the most urgent tasks for the effective therapy of CCA. Here we demonstrated that cyanidin-3-glucoside (C3G), a natural compound found in blackberry and other food products, inhibited hypoxia-induced accumulation of HIF- $1 \alpha$ reporter activity and protein expression in human CCA cells. Furthermore, C3G exerted a strong apoptotic effect and did not induce any cell proliferation. In addition, C3G pre-treatment of CCA cells significantly reduced the hypoxia induced EPO and VEGF mRNA levels without affecting the expression of HIF-1 $\alpha$ mRNA. This research would provide a significant contribution to develop a non/less toxic, high efficiency natural product for the treatment of CCA.

\section{ACKNOWLEDGMENT}

This study was supported by Science and Technology Research project (201548), the Education Department of Jilin province, China. The first two authors contributed equally to this work' in here.

\section{REFERENCES}

1. Blechacz, B., M. Komuta, T. Roskams and G.J. Gores, 2011. Clinical diagnosis and staging of cholangiocarcinoma. Nat. Rev. Gastroenterol. Hepatol., 8: 512-522.

2. Banales, J.M., V. Cardinale, G. Carpino, M. Marzioni and J.B. Andersen et al., 2016. Expert consensus document: Cholangiocarcinoma: Current knowledge and future perspectives consensus statement from the European network for the study of cholangiocarcinoma (ENS-CCA). Nat. Rev. Gastroenterol. Hepatol., 13: 261-280.

3. Khan, S.A., B.R. Davidson, R. Goldin, S.P. Pereira and W.M. Rosenberg et al., 2002. Guidelines for the diagnosis and treatment of cholangiocarcinoma: Consensus document. Gut, 51: vi1-vi9.

4. Yuan, H., Q. Ma, L. Ye and G. Piao, 2016. The traditional medicine and modern medicine from natural products. Mol., Vol. 21. 10.3390/molecules21050559.

5. Olivas-Aguirre, F.J., J. Rodrigo-Garcia, N.D. Martinez-Ruiz, A.I. Cardenas-Robles and S.O. Mendoza-Diaz et al., 2016. Cyanidin-3-O-glucoside: Physical-chemistry, foodomics and health effects. Molecules, Vol. 21, No. 9. 10.3390/molecules21091264.

6. Ferrari, D., F. Cimino, D. Fratantonio, M.S. Molonia and R. Bashllari et al., 2017. Cyanidin-3-O-Glucoside modulates the in vitro inflammatory crosstalk between intestinal epithelial and endothelial cells. Mediators Inflamm., Vol. 2017. 10.1155/2017/3454023.

7. Chen, P.N., S.C. Chu, H.L. Chiou, C.L. Chiang, S.F. Yang and Y.S. Hsieh, 2005. Cyanidin 3-glucoside and peonidin 3glucoside inhibit tumor cell growth and induce apoptosis in vitro and suppress tumor growth in vivo. Nutr. Cancer, 53: 232-243.

8. Ding, M., R. Feng, S.Y. Wang, L. Bowman and Y. Lu et al., 2006. Cyanidin-3-glucoside, a natural product derived from blackberry, exhibits chemopreventive and chemotherapeutic activity. J. Biol. Chem., 281: 17359-17368.

9. Horsman, M.R. and P. Vaupel, 2016. Pathophysiological basis for the formation of the tumor microenvironment. Front. Oncol., Vol. 6. 10.3389/fonc.2016.00066.

10. Zhang, Y., Y. Xu, J. Ma, X. Pang and M. Dong, 2017. Adrenomedullin promotes angiogenesis in epithelial ovarian cancer through upregulating hypoxia-inducible factor-1alpha and vascular endothelial growth factor. Sci. Rep., Vol. 7. 10.1038/srep40524.

11. Tohme, S., H.O. Yazdani, Y. Liu, P. Loughran and D.J. van der Windt et al., 2017. Hypoxia mediates mitochondrial biogenesis in hepatocellular carcinoma to promote tumor growth through HMGB1 and TLR9 interaction. Hepatology, 66: 182-197. 
12. Roscigno, G., I. Puoti, I. Giordano, E. Donnarumma and V. Russo et al., 2017. MiR-24 induces chemotherapy resistance and hypoxic advantage in breast cancer. Oncotarget, 8: 19507-19521.

13. Semenza, G.L., 2009. Regulation of Oxygen homeostasis by Hypoxia-Inducible Factor 1. Physiology, 24: 97-106.

14. Semenza, G.L., 2014. Oxygen sensing, hypoxia-inducible factors and disease pathophysiology. Annu. Rev. Pathol., 9: 47-71.

15. Jin, X., H.R. Jin, D. Lee, J.H. Lee, S.K. Kim and J.J. Lee, 2008. A quassinoid $6 \alpha$-tigloyloxychaparrinone inhibits hypoxiainducible factor-1 pathway by inhibition of eukaryotic translation initiation factor $4 \mathrm{E}$ phosphorylation. Eur. J. Pharmacol., 592: 41-47.

16. Williams, C.A. and R.J. Grayer, 2004. Anthocyanins and other flavonoids. Nat. Prod. Rep., 21: 539-573.

17. Kong, J.M., L.S. Chia, N.K. Goh, T.F. Chia and R. Brouillard, 2003. Analysis and biological activities of anthocyanins. Photochemistry, 64: 923-933.

18. Azzini, E., J. Giacometti and G.L. Russo, 2017. Antiobesity effects of anthocyanins in preclinical and clinical studies. Oxid. Med. Cell Longev., Vol. 2017. 10.1155/2017/2740364

19. Anwar, S., A. Speciale, D. Fratantonio, M. Cristani, A. Saija, F. Virgili and F. Cimino, 2014. Cyanidin-3-O-glucoside modulates intracellular redox status and prevents HIF-1 stabilization in endothelial cells in vitro exposed to chronic hypoxia. Toxicol. Lett., 226: 206-213.

20. Wang, H., T.O. Khor, L. Shu, Z.Y. Su, F. Fuentes, J.H. Lee and A.N. Kong, 2012. Plants vs. Cancer: A review on natural phytochemicals in preventing and treating cancers and their druggability. Anticancer Agents Med. Chem., 12: 1281-1305.

21. Maru, G.B., R.R. Hudlikar, G. Kumar, K. Gandhi and M.B. Mahimkar, 2016. Understanding the molecular mechanisms of cancer prevention by dietary phytochemicals: From experimental models to clinical trials. World J. Biol. Chem., 7: 88-99.
22. Tsuda, T., K. Shiga, K. Ohshima, S. Kawakishi and T. Osawa, 1996. Inhibition of lipid peroxidation and the active oxygen radical scavenging effect of anthocyanin pigments isolated from Phaseolus vulgaris L. Biochem. Pharmacol., 52: 1033-1039.

23. Shanmugam, M.K., J.H. Lee, E.Z.P. Chai, M.M. Kanchi and S. Kar etal., 2016. Cancer prevention and therapy through the modulation of transcription factors by bioactive natural compounds. Seminars Cancer Biol., 40: 35-47.

24. Wang, G.L., B.H. Jiang, E.A. Rue and G.L. Semenza, 1995. Hypoxia-inducible factor 1 is a basic-helix-loop-helix-PAS heterodimer regulated by cellular $\mathrm{O} 2$ tension. Proc. Natl. Acad. Sci., 92: 5510-5514.

25. Ader, I., B. Malavaud and O. Cuvillier, 2009. When the sphingosine kinase 1/sphingosine 1-phosphate pathway meets hypoxia signaling: New targets for cancer therapy. Cancer Res., 69: 3723-3726.

26. Giaccia, A., B.G. Siim and R.S. Johnson, 2003. HIF-1 as a target for drug development. Nat. Rev. Drug Discov., 2: 803-811.

27. Dengler, V.L., M. Galbraith and J.M. Espinosa, 2014. Transcriptional regulation by hypoxia inducible factors. Crit. Rev. Biochem. Mol. Biol., 49: 1-15.

28. Conway, E.M., D. Collen and P. Carmeliet, 2001. Molecular mechanisms of blood vessel growth. Cardiovasc. Res., 49: 507-521.

29. Debeljak, N., P. Solar and A.J. Sytkowski, 2014. Erythropoietin and cancer: The unintended consequences of anemia correction. Front. Immunol., Vol. 5. 10.3389/fimmu.2014.00563.

30. Carbajo-Pescador, S., R. Ordonez, M. Benet, R. Jover, A. GarciaPalomo, J.L. Mauriz and J. Gonzalez-Gallego, 2013. Inhibition of VEGF expression through blockade of Hif1 $\alpha$ and STAT3 signalling mediates the anti-angiogenic effect of melatonin in HepG2 liver cancer cells. Br. J. Cancer, 109: 83-91.

31. Jin, W., Z. Lin, X. Zhang, L. Kong and L. Yang, 2015. Effects and mechanism of recombinant human erythropoietin on the growth of human breast cancer MDA-MB-231 cells in nude mice. Pathol. Res. Pract., 211: 570-576. 